\title{
El desarrollo de la competencia narrativa en estudiantes nativos de español. Análisis e interpretación de una investigación con referentes fílmico-literarios
}

The development of narrative competence in native Spanish students. Analysis and interpretation of a research with filmic and literary referents

\author{
María Teresa Martín Sánchez ${ }^{1}$ \\ tmartin@unisa.it \\ Universidad de Salerno, Italia
}

\section{Resumen:}

En este trabajo se presenta un modelo de análisis de la competencia narrativa en estudiantes de español como lengua madre. El objetivo es diseñar y convalidar empíricamente un modelo de producción y de análisis de la competencia comunicativa oral y escrita de nivel B2 de estudiantes que aprenden español como lengua extranjera y de estudiantes españoles que estudian la propia lengua en Educación Secundaria. La novedad de este trabajo interdisciplinario consiste en el innovador enfoque semiótico intertextual que se obtiene gracias a la relación entre cine y literatura, que desarrollan, gracias a diferentes estrategias narratológicas, el mismo referente semántico. Otro aspecto original de este trabajo es el hecho de que no se

\begin{abstract}
:
This paper was written as it was felt there was a need to create a simple but exhaustive system of assessment to evaluate the narrative skills of students doing Spanish as a foreign language and those studying it as their mother tongue.

The main aim of this paper is to create and appraise a model capable of producing and evaluating written and oral skills of Italian B2 level students learning Spanish as a foreign language and Spanish students studying Spanish as part of their B2 level curriculum.

What distinguishes this paper is its innovative semiotic approach which crossfertilizes the relationships between cinema and literature. Although two different narrative techniques are employed, these
\end{abstract}

1 Dirección para correspondencia (correspondence address):

María Teresa Martín Sánchez. DIPSUM (Departamento de estudios humanísticos). Universidad de Salerno. Via Gennaro Niglio, 19. 80056 Ercolano, Nápoles (Italia). 
El desarrollo de la competencia narrativa en estudiantes nativos de español. Análisis e interpretación de una investigación con referentes fílmico-literarios

María Teresa Martín SánChez

focaliza en compartimentos estancos (texto literario / texto fílmico), sino que cultiva un aspecto de correlato intertextual. Se ha creado un modelo denominado COEN: se trata de un modelo didáctico de desarrollo de la Competencia oral y escrita de textos narrativos en español. COEN se ha pensado para poder aplicarlo posteriormente a estudiantes de español como lengua extranjera y a estudiantes nativos de Educación Superior que poseen un nivel de competencia B2. El modelo aúna la producción y la evaluación de la competencia discursiva oral y escrita de textos narrativos. Por motivos de espacio se presentan los resultados del análisis de las producciones escritas de los discentes españoles.

\section{Palabras clave:}

Competencia narrativa; interdisciplinariedad; evaluación; rúbricas. two elements develop the same semantic reference. Another original feature is that this study is not based on a simple comparison between the two genres but rather on the correlation between them. To this extend, a model called C.O.E.N was created. This didactic model concentrates on oral and written competency in Hispanic texts which can be evaluated once students learning Spanish as a second language have reached a B2 level, but also on mother tongue Spanish students who have reached the same level. This method links production and evaluation of oral and written competency in narrative texts. Due to length restrictions, this paper presents only the results of the analysis of Spanish learners' written productions.

\section{Key words:}

Narrative competence; interdisciplinarity; evaluation; rubrics.

\section{Résumé:}

Ce travail présente un modèle d'analyse de la compétence narrative chez des étudiants d'espagnol comme langue maternelle. L'objectif vise la conception et la validation empirique d'un modèle de production et d'analyse de la compétence orale et écrite correspondante au niveau B2. Cette analyse a été réalisée auprès d'étudiants d'espagnol langue étrangère et d'autres qui étudient leur langue maternelle à l'école secondaire. La nouveauté de ce travail interdisciplinaire se trouve dans l'approche sémiotique intertextuelle innovatrice, grâce à la mise en rapport entre le cinéma et la littérature. Ces deux éléments développent le même référent sémantique en déployant différentes stratégies narratologiques. Nous signalerons également un aspect original du travail. En effet, notre travail ne fait pas ressortir la nette séparation entre le texte littéraire et le texte filmique, bien au contraire, nous travaillons l'aspect de la corrélation intertextuelle. Le modèle nommé COEN a été créé dans le but de développer la compétence orale et écrite de textes narratifs en espagnol. De plus, il est prévu que COEN soit appliqué à des étudiants d'espagnol langue étrangère ainsi qu'à des étudiants natifs ayant un niveau de compétence B2. Le modèle vise la production et l'évaluation de la compétence discursive orale et écrite de textes narratifs. Par manque d'espace nous ne présenterons que les résultats de I'analyse des productions écrites des élèves espagnols.

\section{Mots clés:}

Compétence narrative; interdisciplinarité; évaluation; rubrique.

Fecha de recepción: 6-2-2018

Fecha de aceptación: 14-2-2018 


\section{Justificación y marco teórico de la investigación}

La propuesta de esta investigación responde a la necesidad de avanzar en la formulación de modelos didácticos para que las habilidades lingüísticas se transformen en competencias lingüísticas contextualizadas en interacción comunicativa con diversos lenguajes y manifestaciones culturales.

Se analizan aquí narraciones escritas de creación literaria que forman parte de un proyecto más amplio, que comprende un análisis de narraciones escritas y orales realizadas tanto por estudiantes nativos de español, como por estudiantes italianos que estudian español como lengua extranjera, para posteriormente crear una rúbrica de evaluación que sea útil para ambos casos. Por motivos de espacio nos limitaremos a presentar los resultados del análisis de las producciones escritas de los estudiantes españoles nativos.

La novedad de este trabajo interdisciplinar consiste en la nueva orientación de enfoque semiótico intertextual que se le da vinculando el cine y la literatura que desarrollan con estrategias narratológicas diversas el mismo referente semántico, ya que la trasposición de los clásicos de la literatura al cine mudo da al estudiante la posibilidad de inferir el propio bagaje cultural en la narración, ofreciendo la posibilidad de trasladar a la expresión escrita las experiencias significativas que el alumno tiene sobre el tema.

Otro aspecto importante es que no se trabaja en compartimentos estancos (texto literario / texto fílmico) sino que cultiva el correlato intertextual y la producción intertextual basándose en un modelo lecto-literario. El objetivo de esta intervención es proponer en el aula situaciones que pueden desarrollarse en la vida cotidiana, en la que constantemente unimos imágenes y textos para crear nuevas producciones textuales. Además hay que tener en cuenta que la competencia narrativa es, sin lugar a dudas, una de las competencias que más se utilizan fuera del aula, por lo tanto, aprender a narrar es una habilidad imprescindible para la vida cotidiana.

El marco teórico de investigación estudia tres ámbitos científicos en confluencia:

En primer lugar la competencia comunicativa en español tanto de lengua extranjera como nativos, en el ámbito de las competencias clave que indica el Marco Plurilingüe de la Unión Europea, complementarias 
El desarrollo de la competencia narrativa en estudiantes nativos de español. Análisis e interpretación de una investigación con referentes fílmico-literarios María Teresa Martín SánChez

con las precisiones del MCERL en referencia a los niveles de dominio lingüístico, así como en los principios y en la metodología que facilita el Plan Curricular del Instituto Cervantes para la disciplina de español LE/ L2. Se incluye en este apartado la competencia comunicativa desarroIlada en el ámbito de la Educación Literaria basada en la metodología intertextual y en el trabajo con los clásicos.

La Educación Literaria, disciplina que responde a una orientación significativa del aprendizaje de la literatura a través de tareas comunicativas de comprensión y expresión literaria en las que lector dialoga con la obra y su autor. Por tanto, lo importante no es tanto el análisis estructural de las características del texto en cuestión ni tampoco la indagación en referentes explicativos biográficos o estilísticos de su autoría como la oportunidad que este encuentro brinda para desarrollar las competencias lectora y escritora del lector en un diálogo franco entre su cultura y la que la obra le brinda.

En esta línea de actuación, la Educación Literaria se beneficia de la gran versatilidad que tiene la literatura para absorber cualquier tipología textual en su circuito imaginativo y, por tanto, desde su estudio cabe preparar a los aprendices para leer mejor los diversos discursos sociales, según ha señalado Teresa Colomer (2005). Se añade a su observación la opinión de Mendoza (2004), quien indica que la metodología más efectiva de la educación literaria es la intertextual.

Ciertamente, la Educación Literaria no se enseña, sino que "se vive, se experimenta, se asimila, se percibe, se lee" (Mendoza, 2001, p. 48). Pero es necesario desvincular esta ciencia de versiones simplistas y dicotómicas que reducen su incidencia a una mera animación lectora o escritora por las que se aprende de modo placentero hasta el punto de convertir el placer en su centro de interés. Bombini (2005) ha censurado estas "pedagogías del placer" que ocasionan reacciones pasivas en los alumnos ante las obras literarias, lo cual redunda precisamente en la inhabilitación de lo que debe ser ante todo la Educación Literaria: la formación competente de lectores y escritores que asumen de modo personal y cualificado las características del discurso literario.

A juicio de Caro y González (2013), la dinámica intertextual e hipertextual de la literatura es la que desmantela la citada coerción academicista. Ponen como ejemplo de su tesis la pervivencia de los clásicos en la actualidad gracias a la riqueza que proporciona su perspectivismo lector y recomiendan encauzar la educación literaria hacia proyectos y tareas 
donde la obra literaria conecte de modo personal y diverso con la vida de cada lector singular.

La metodología intertextual de la educación literaria proviene de una corriente de estudios semióticos sobre el diálogo entre la producción y la recepción textual, entre las artes y las disciplinas, y en especial en un entendimiento transversal de la literatura, donde destacan la labor pionera de Bajtín (1986) y del grupo Tel Quel (VV.AA, 1968), y el despliegue de la Estética de la Recepción (Jauss, 1976; Eco, 1981) y de los estudios sobre la hipertextualidad como trascendencia textual (Genette, 1989). Es imprescindible concebir la Educación Literaria como la capacitación para que el lector interactúe con el texto y el autor. Por ello, mediante la lectura y escritura de textos literarios, los aprendientes hacen crecer su competencia comunicativa para la vida con motivos y verdades estimulantes. Así que la mayor innovación educativa en la Educación Literaria es la planificación estratégica dirigida al desarrollo de la creatividad.

Importa contar con la metodología del "intertexto lector" -concepto ideado por Mendoza (2001) y ampliado por Romea (2003) y el grupo FRAC- y con su expansión interdisciplinar por medio de los estudios centrados en la viabilidad de los modelos ekfrásticos, pues en ellos la literatura se desenvuelve en interacción retórica con las imágenes provenientes de las artes plásticas y audiovisuales.

Con otras palabras, desde una óptica intertextual de la Educación Literaria se precisa trabajar la competencia literaria activando el intertexto lector de cada persona en el proceso comprensivo-interpretativo de la cognición lectora porque, gracias a él, se integran y combinan las acciones primarias y superiores del pensamiento humano: desde la identificación, la asociación y la conexión hasta la síntesis reflexiva y la creatividad en los espacios de la lectura y la escritura.

También se considera la relación significativa y estructural de la literatura con las artes y la retórica que posibilita el comparativismo ekfrástico. La metodología de la "ékfrasis" (la ilusión o inspiración que un texto icónico provoca para realizar un texto verbal, resumida en el célebre lema horaciano ut pictura poiesis) promueve una nueva visión de la educación literaria abierta semióticamente a otros lenguajes y disciplinas desde el intertexto del intérprete que construye y recrea significados.

Así lo han demostrado otros estudios ekfrásticos de Mendoza (2000) y Caro Valverde (2007) aplicados a la correlación de la literatura con las artes plásticas exhibidas en los museos, así como las profusas publica- 
El desarrollo de la competencia narrativa en estudiantes nativos de español. Análisis e interpretación de una investigación con referentes fílmico-literarios María Teresa Martín SánChez

ciones de Guerrero (2008; 2015), experto destacado en el estudio del comparativismo ekfrástico.

El empleo del modelo ekfrástico en las aulas es motivador y estimula la creatividad a partir del descubrimiento donde, como bien indica Molina (2015, p. 399), "la imagen inspira a la palabra" más allá de la imitación descriptiva, hacia la libertad expresiva de la imaginación en diversos géneros y formatos gracias a la comunicación libre que ejerce el proceso lector anteriormente descrito. También estimula el trabajo interdisciplinar en el aula al combinar elementos plásticos y verbales, lo cual contribuye a la maduración en un aprendizaje globalizado del proceso comunicativo del arte.

En segundo lugar, el tratamiento de la textualidad fílmica.

En el siglo XXI, la alfabetización audiovisual ocupa un lugar preeminente en la educación, puesto que la sociedad actual usa la imagen como transporte de relaciones simbólicas para configurar la cultura de la Sociedad del Conocimiento y necesita estrategias para que las personas la empleen con autonomía y valores democráticos. Para ello, es necesario que el mundo educativo incorpore con rigor científico el estudio del hipertexto como la lógica lectora cotidiana del medio digital (Romea, 2008).

Con el inicio del nuevo milenio se ha iniciado un intenso reclamo del material cinematográfico como recurso educativo con propuestas concretas para el cultivo de la intertextualidad (Romea, 2003), de la interculturalidad a través de cinefórum (Jiménez, 2005; Pons, 2009) y del aprendizaje de lenguas y sus culturas. El cine sigue siendo, pues, un medio de gran interés pedagógico y demanda en el mundo educativo una atención exclusiva para aprender a ver y hacer cine $y$, a partir de este, aprender conocimientos de diversas disciplinas (Fox,y Lambirth, 2012).

Son numerosas las iniciativas reivindicativas del estudio competencial del cine en conjunción con la lengua y la literatura. Pionera y permanente es la labor analítica de su recepción lectora compartida que ha sido ejercida por Romea $(1998 ; 2003)$ y la labor de realizada por Martínez-Salanova $(1998 ; 2001)$ para fomentar su didáctica estratégica.

Desde un enfoque integral de la educación próximo a este planteamiento humanista de las relaciones entre cine y literatura, por parte de las profesoras Caro y González existe una iniciativa puntera en el desarrollo de las competencias básicas a través de la conjunción entre cine y literatura y, de modo destacado, la competencia comunicativa desde 
el enfoque hipertextual que dicha conjunción y su difusión mediática comporta (Caro y González, 2012; González y Caro, 2012; González, 2013; Caro, 2014). Ambas han desarrollado una línea de investigaciónacción en el aula donde los alumnos leen textos literarios y fílmicos y los comentan en su interacción a través de foros de aula, tras los que emprenden un taller de creación literaria y/o de creación de películas cuyos textos son generados por los propios alumnos.

En tercer lugar, la narración en el aprendizaje de la lengua y de la cultura. Se procede, por lo tanto, siguiendo las grandes líneas del estudio prototípico del relato y analizando lingüísticamente el texto narrativo, para individuar la macroestructura y el modelo descriptivo, que sirven como puntos de referencia para poder estudiar más tarde la estructura textual narrativa en sus rasgos característicos.

\section{Metodología}

La metodología didáctica que sostiene el marco empírico de este estudio es la investigación en la acción. Se trata de una línea de investigación surgida de las ciencias sociales en los años 40 e iniciada por el psicólogo social Lewin (1973), quien describe la investigación-acción como una espiral de pasos. Más tarde, Kemmis (1984) la define como una forma autoreflexiva de indagación que realizan quienes participan en las situaciones sociales o educativas y las instituciones en que estas prácticas se realizan. Por último, Latorre (2003, p. 24) la representa como "Una indagación práctica realizada por el profesorado de forma colaborativa, con la finalidad de mejorar su práctica educativa a través de ciclos y reflexión".

En nuestro trabajo nos remitimos a las características de la investigación-acción descritas por Kemmis y McTaggart (1988):

- Implica ciclos de planificación acción observación reflexión.

- Es participativa. Se trabaja para mejorar las prácticas desarrollando estos ciclos.

- Es colaborativa: se forma un grupo de personas que se implican en el proceso de enseñanza/aprendizaje.

- Se crean comunidades autocríticas en la medida que participan y colaboran en el proceso de enseñanza/aprendizaje valorando su propia trayectoria de conocimientos adquiridos. 
El desarrollo de la competencia narrativa en estudiantes nativos de español. Análisis e interpretación de una investigación con referentes fílmico-literarios María Teresa Martín SánChez

- Se analizan críticamente las situaciones educativas planteadas y ocasionadas.

- Se teoriza sobre la práctica.

- Se someten a prueba las ideas, las prácticas y las suposiciones.

- Implica registrar recopilar y analizar lo que ocurre.

- Se procede progresivamente avanzando hacia cambios más amplios y de mejora de la calidad del trabajo didáctico.

El trabajo se basa también en los modelos metodológicos de la lingüística de corpus, que recoge muestras reales del uso de la lengua -en este caso transcripciones de textos escritos de carácter narrativo emitidos en el aula- cuyo fin es evaluar el nivel de las narraciones para crear una rúbrica de evaluación que indique los descriptores más significativos del análisis narratológico y lingüístico de la narración, a fin de que sirvan como elementos de apoyo para que los docentes puedan evaluar de forma rápida y eficaz las producciones de los discentes.

Además, de acuerdo con el modelo metodológico recomendado por el MCER (2002), se sigue el enfoque por tareas (Nunan, 1997; Zanón 1990; Zanón y Estaire 1990; Fernández 2001) a fin de generar en el aula auténticos procesos de comunicación a partir de tareas didácticas contextualizadas donde los alumnos se motiven ante acciones con resultados tangibles, tomen conciencia de los procesos de aprendizaje y se hagan responsables de los mismos. Se ha querido tomar aquí la idea de tarea de Puren (2004, p. 33), quien la define como una "unidad de sentido dentro del proceso conjunto de aprendizaje y enseñanza", que deja espacio a la adecuación de la tarea al entorno de aprendizaje. De esta manera se pasa del concepto de tarea, (lo que hacen los alumnos en clase) al concepto de acción (lo que tienen que hacer con la lengua en la sociedad), puesto que las actividades propuestas en este trabajo pueden considerarse como una tarea (en el aula) que prepara o entrena a los alumnos para una acción (en la sociedad).

Para la presente investigación se ha creado un modelo que se ha denominado COEN: se trata de un modelo didáctico de desarrollo de la Competencia Oral y Escrita de textos Narrativos en español. El modelo COEN se ha diseñado para su posterior aplicación tanto en estudiantes de español lengua extranjera, como para alumnos de educación secundaria nativos que cursan lengua castellana y literatura española en España y que tienen un nivel de competencia B2, según el marco común 
europeo de referencia para las lenguas. El modelo aúna la producción y la evaluación de la competencia discursiva oral y escrita de textos narrativos.

El modelo de análisis se basa en las necesidades que se han observado durante trabajos anteriores (Martin, Pascual, 2012) y en el modelo de Caro y González (2012) al que se le han aportado las modificaciones necesarias para que sirviera como referente de la evaluación de la competencia narrativa. Además es de fácil aplicación en la práctica docente. Tal modelo puede observarse en la tabla 1

Tabla 1. Modelo de análisis de textos narrativos de español nivel B2 a partir de referentes fílmico-literarios.

\begin{tabular}{|c|c|c|}
\hline Coherencia & Cohesión & Adecuación: \\
\hline $\begin{array}{l}\text { I. Cantidad de infor- } \\
\text { mación } \\
\text { II. Estructura de infor- } \\
\text { mación: } \\
\text { - proceso prototípico } \\
\text { - Inserción de se- } \\
\text { cuencias (Descripti- } \\
\text { va / dialogal) } \\
\text { III. Calidad de la infor- } \\
\text { mación } \\
\text { - progresión temática } \\
\text { (lógica) } \\
\text { - relación con el } \\
\text { referente textual } \\
\text { (congruencia) }\end{array}$ & 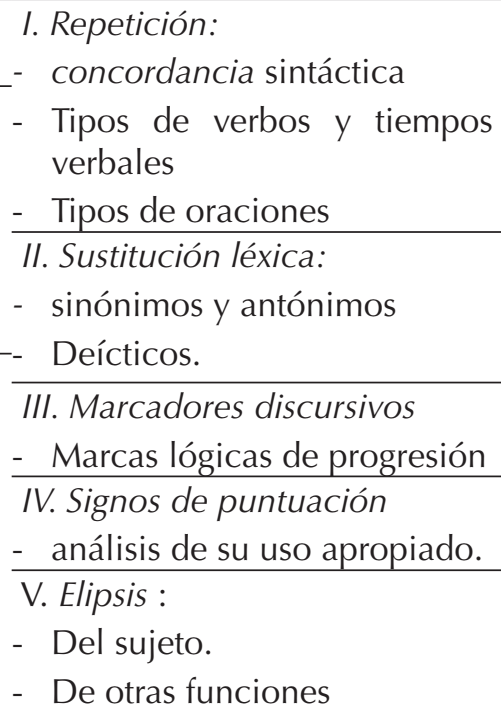 & $\begin{array}{l}\text { I. Registro: } \\
\text { - género y nivel de } \\
\text { lengua } \\
\text { II. Propósito: } \\
\text { - punto de vista y } \\
\text { - función comunica- } \\
\quad \text { tiva } \\
\text { III. Presentación: } \\
\text { - ortografía, } \\
\text { - tipografía y } \\
\text {-- caligrafía (Correc- } \\
\text { ción) }\end{array}$ \\
\hline
\end{tabular}

En este modelo de análisis organizado en función de las cualidades textuales fundamentales para promover la comunicación (coherencia, cohesión y adecuación) se recogen los criterios del Marco Común Europeo de Referencia para las Lenguas (2002), así como del Plan Curricular del Instituto Cervantes (2006) en lo referente a los ítems que se ha decidido evaluar y, sobre todo, a la descripción de las habilidades y de las capacidades que deben tener los usuarios de la lengua en un nivel B2 / B2+. Asimismo en la configuración del modelo ha influido el esquema de textualización procedente de la propuesta del MEC para la evaluación de diagnóstico en competencias. 
El desarrollo de la competencia narrativa en estudiantes nativos de español. Análisis e interpretación de una investigación con referentes fílmico-literarios María Teresa Martín SánChez

En atención a la valoración científica de la eficacia metodológica de la rúbrica en los procesos de evaluación formativa (Jonsson, A. y Svingby, 2007; Panadero, Alonso-Tapia y Reche, 2013), se ha diseñado un modelo de rúbrica que contempla tanto la modalidad oral como la escrita en sus tres aspectos fundamentales, es decir, coherencia, cohesión y adecuación. En cada una de ellas se detallan, de forma sintética pero eficaz, los niveles de desempeño a los que llega el alumno, que van de insuficiente a excelente, y de logro con precisiones que oscilan entre 0 y 10 de acuerdo con los indicadores de aprendizaje que clasifican las evidencias analizadas, de manera que su implementación sea fácil de aplicar para el profesor y fácil de entender para el alumno.

El objetivo del análisis es el de comprobar la validez de las rúbricas de evaluación. De este modo, el modelo COEN se manifiesta como un modelo novedoso en el ámbito de la enseñanza-aprendizaje del español, pues en él interaccionan el cine y la literatura. Además, hay que señalar que el modelo COEN es aplicable tanto a estudiantes nativos como a estudiantes no nativos de español, y que reúne en sí todos los aspectos relacionados con la narración

La implementación del modelo se ha realizado en varias fases que se explican brevemente a continuación:

- Creación de una tarea que conjugue los dos aspectos mencionados arriba literatura y cine, es decir, el aspecto semiótico y el textual, y a la vez relacionar literatura y lengua en el aula, sin trabajarlas en compartimentos estancos.

- Creación por parte de los alumnos de textos narrativos.

- Creación de un corpus que contenga las narraciones de los informantes.

- Análisis del corpus.

- Creación de unas rúbricas de evaluación y su posterior implementación.

- Comprobación de la validez de las rúbricas gracias al análisis del corpus.

El modelo prevé el visionado de dos tráileres basados en el célebre episodio de los molinos de viento contenido en el capítulo VIII de la primera parte del Quijote de Miguel de Cervantes: se trata específicamente de Don Quixote de Ub Iwerks (1934), que es una versión muda de dibujos animados, y de la obra de Orson Welles Don Quijote (1922), 
la cual ha pasado silenciada. También prevé la lectura placentera del mencionado capítulo VIII de la primera parte de la obra cervantina.

Tras el visionado, los alumnos narran lo que han visto. De este modo, se ponen en juego los aspectos cognitivos que conjugan el correlato textual con la semiótica de las imágenes. Posteriormente, los alumnos escriben una narración sobre lo que han leído y visto.

\section{Participantes}

Los informantes de la investigación cursaban primero de Bachillerato dentro de la modalidad de Excelencia denominada "Bachillerato de Investigación" en el instituto de Enseñanza superior Infante Don Juan Manuel de Murcia (a.a. 2013-2014). Se eligió esta modalidad por considerarla más afín a los criterios que el Marco Común Europeo de Referencia para las Lenguas dicta para un dominio de la lengua de nivel B2/B2+. La edad media de los participantes oscila entre 16 y 17 años. Es requisito indispensable que todos tengan como lengua materna el español. Cabe recordar aquí que el MCER nació para clasificar los niveles de dominio de la lengua materna y, solo posteriormente, se adaptó para clasificar los niveles de dominio de las lenguas extranjeras.

Para certificar el nivel de lengua se ha empleado como instrumento de recogida de datos sobre sus conocimientos previos la realización de una entrevista semiestructurada al docente que tiene en responsabilidad la formación del grupo de alumnos implicados en el área de conocimiento de Lengua castellana y Literatura. Para la selección de la muestra, se utilizó una técnica de muestreo no probabilístico intencional y accidental (Albert, 2007). La muestra constituye el 0,26\% de la población total, por lo tanto plenamente representativa.

En la tabla 2 se especifican las características sociolingüísticas de los informantes españoles.

Tabla 2. Análisis sociológico de los informantes españoles.

\begin{tabular}{ll}
\hline País de origen & España \\
\hline Lugar de residencia & Murcia capital \\
\hline Lengua materna & castellano \\
\hline Edad & $16 / 17$ años \\
\hline Sexo & Hombre / mujer \\
\hline
\end{tabular}


El desarrollo de la competencia narrativa en estudiantes nativos de español. Análisis e interpretación de una investigación con referentes fílmico-literarios María Teresa Martín Sánchez

\begin{tabular}{ll}
\hline Nivel de estudios & 1 curso bachillerato de investigación \\
\hline Nivel de español & 3 horas semanales nivel satisfactorio (media de 8) \\
\hline Otras lenguas extranjeras & Inglés, francés \\
\hline
\end{tabular}

\section{Corpus}

El corpus que aquí se estudia está formado por 15 narraciones escritas. El total de palabras es de 7516, con una media de 501 palabras por informante. La más larga contiene 634 palabras y la más corta, 407.

Para etiquetar las narraciones se ha optado por un código que recoge los siguientes datos: el centro de procedencia (MU de Murcia), indicación del curso en el que están (1), Identificación del tipo de prueba (E para escrito); e identificación del informante con las dos primeras letras del nombre y las dos primeras del apellido.

\section{Resultados y discusión}

Se explicitan aquí los resultados del análisis, tras la aplicación del modelo de evaluación.

\section{Análisis de la coherencia}

En relación con la coherencia se han valorado los aspectos de la información textual basada en los criterios de cantidad, estructura y calidad. Se puede observar que el $100 \%$ de las producciones cumplen el requisito de cantidad, pues los discentes han empleado las textualidades fílmica y literaria para construir sus narraciones.

Con respecto a la estructura, todas las producciones siguen el proceso prototípico del relato narrativo indicado en el PCIC. Las secuencias descriptivas aparecen en tres relatos (20\%), como puede verse en el ejemplo 1.

Ejemplo 1:

MU1EPEPE (líneas 19-11)

Estas criaturas tenian un solo ojo, eran feas como ellas solas, con unos brazos gigantes. Su olor era fetido, apestaban mas que mil porquerizas 
Las secuencias dialogales aparecen en 6 de los 15 textos, lo que equivale al $40 \%$ del total, tanto en estilo indirecto, como directo, si bien ningún informante sigue las reglas tipográficas que el Plan curricular indica para el diálogo, como puede observarse en el ejemplo 2.

\section{Ejemplo 2:}

MU1EGUGO (líneas 6-9)

Llegaron así, sobre que caballero merecía más renombre, hasta una amplia esplanada plagada de molinos de viento. "Mire, amo mío, que las aventuras ya empiezan a aparecérsenos", dijo Sancho. "¿A que os referís?" respondió don Quijote. "A los terribles gigantes que en nuestra marcha se interponen" dijo Sancho, con un tono más esperanzado que temeroso, al verse a tiro de una posible aventura.

\section{Análisis de la adecuación}

En relación a la adecuación, se analizan los puntos referidos al registro, el propósito y la presentación.

Todos los informantes han mantenido un registro culto formal. Por lo que se refiere al propósito, el 100\% de las producciones siguen las convenciones genéricas. Los informantes, en la recreación fílmico-literaria añaden detalles relacionados con los conocimientos que tienen de la obra cervantina. Por ello, se ha considerado que tienen una función informativa.

Respecto a la presentación, la tipografía y la caligrafía son correctas. El 53.3\% de los estudiantes comete errores de ortografía que se manifiestan sobre todo en la omisión de los acentos y en la confusión de letras $v$ y $b$ y de /l e y, como se ilustra en el ejemplo 3.

Ejemplo 3: MU1EGUGO (líneas 18-21)

Tal fue la fuerza que rompíose el cayado, y viendose indefenso apresurose a huir del gigante cabalgando entre el aparentemente bacío hueco que había entre sus piernas.

\section{Análisis de la cohesión}

En el análisis del uso de los recursos verbales que cohesionan el texto por su repetición, un $40 \%$ de los informantes (6 narraciones) comete errores de concordancia gramatical, que se manifiestan, en su mayoría, 
El desarrollo de la competencia narrativa en estudiantes nativos de español. Análisis e interpretación de una investigación con referentes fílmico-literarios

en omitir o añadir la preposición correspondiente (ejemplo 4); en poner el pronombre complemento equivocado; en errores de concordancia, como puede observarse en el ejemplo 5 y en no reduplicar el pronombre personal de objeto directo.

Ejemplo 4:

MU1EGUGO (línea 15)

y blandiendo su cayado como si la Tizona del Cid se tratase.

Ejenplo 5:

MU1EPEPE (líneas 9-10)

Pero no cualquier tipo de gigante, sino el peor de todo.

En relación a los tipos verbales de la narración, en las producciones de los informantes españoles aparecen, en el 100\% de ellas, todas las tipologías que se mencionan para el nivel B2 (inicio, continuación finalización, cambio, localización, posición existencia, cualidad general y repetición), como se ilustra en los ejemplos 6 y 7 :

Ejemplo 6:

MU1EAGRA (líneas 2-3)

ambos decidieron volver al lugar de lo ocurrido, haciendo uso de sus camellos, ya que se encontraban en Arabia.

\section{Ejemplo 7:}

MU1EPEPE (línea 26)

Al final, Quijote le clavo la espada en el corazón del gigante y consiguio derrotarlo

En relación a la cohesión de los verbos en sus tiempos, cometen errores de concordancia temporal 8 informantes, mientras que el $46.6 \%$ de las narraciones han mantenido la concordancia temporal (ejemplo 8).

\section{Ejemplo 8:}

MU1EALCA (líneas 34-35)

"Hay que ver Sancho que buena lección dimos a ese genio, pero andemos con cuidado que no será esta la última vez que lo veremos". 
Las oraciones de los textos aparecen bien cohesionadas en los elementos iterativos que las identifican. Respecto a la cohesión por sustitución léxica, se han analizado el uso de sinónimos y antónimos; de la deíxis espacial y personal; y el uso de catáforas.

La sustitución léxica se realiza tanto por sinónimos, como por hiperónimos como caballo para Rocinante (ejemplo 9):

Ejemplo 9:

MU1EALCA (línea 28)

Y descendiendo del caballo avanzó espada en mano hacia el molinero con gran alborio,

Los apelativos para Don Quijote son: caballero, amo, amigo, señor, hidalgo, compañero, el justo; mientras que los apelativos para Sancho Panza son: amigo, jinete y escudero, como en el ejemplo 10:

Ejemplo 10:

MU1EJUMA (línea 11-12)

Media hora después de que Sancho partiera, no había vuelto, asi que Don

Quijote salió en busca de su amigo lanza y escudo en mano,

En los resúmenes de los informantes españoles no aparecen antónimos.

Respecto a la deíxis espacial no aparece la combinación adverbios deícticos para concretar o intensificar más el lugar, aunque sí aparecen elementos deícticos tales como los adverbios allí, ahí y aquí. En deíxis personal aparecen los pronombres personales sujeto que enfatizan la participación de la persona en la acción en 9 textos (60\%), como se observa en el ejemplo 11; mientras que el se mitigador de responsabilidad no aparece en ninguno de los textos del corpus escrito de Murcia.

Ejemplo 11:

MU1OAGRA (línea 26)

Finalmente, Desmond aclaró que él no había visto a los gigantes en ningún momento.

Todos los textos aparecen cohesionados gracias al uso que se hace de la elipsis, que aparece en todos los textos, sobre todo omitiendo la 
El desarrollo de la competencia narrativa en estudiantes nativos de español. Análisis e interpretación de una investigación con referentes fílmico-literarios

María Teresa Martín Sánchez

información referida al sujeto o al sintagma verbal, como se aprecia en el ejemplo 12:

\section{Ejemplo 12:}

MU1OAGRA (líneas 3-4)

Finalmente, Desmond aclaró que él no había visto a los gigantes en ningún momento. Sin embargo, don Quijote y Sancho sí.

Con respecto a la catáfora, en el Plan curricular del Instituto Cervantes para el nivel B2 se consideran los pronombres personales, demostrativos, posesivos, cuantificadores y adverbios, con función catafórica. Este aspecto aparece en el $100 \%$ de los textos, ya sea tanto por el uso de pronombres personales y demostrativos, como de posesivos y cuantificadores, como puede observarse en el ejemplo 13:

\section{Ejemplo 13:}

MU1OPADU (línea 6)

Pero lo más extraño era el sistema que tenía en su frontal

En relación con los marcadores discursivos previstos para el nivel B2 por el Plan curricular del Instituto Cervantes en el corpus escrito de Murcia no aparecen estructuradores ni reformuladores. Los conectores justificativos están presentes en 6 textos (40\%), aparecen, de los señalados en el inventario, puesto que y ya que (ejemplo 14). También aparecen los conectores contraargumentativos en cambio y a pesar de. Como operadores discursivos aparece el focalizador incluso y el de refuerzo argumentativo por supuesto. Siete de los textos analizados (46.66\%) utilizan marcadores que se indican como propios del nivel B2.

Ejemplo 14: MU1EPAPE (líneas 23-24)

$\mathrm{Al}$ enterarse este joven de lo sucedido arremetió contra el destructor del molino retandole a un duelo como marcan las leyes de caballería puesto que él también había sido nombrado caballero hacía apenas unos días,

Tras haber analizado sistemáticamente todos los textos en relación a los parámetros indicados por el Plan Curricular del Instituto Cervantes para el nivel de competencia B2, podemos Ilegar a las siguientes consideraciones: 
- Los textos escritos cumplen los parámetros requeridos para el nivel con respecto a la coherencia de los textos narrativos. Respecto a la inserción de secuencias, no aparecen en todos los textos, pero recordemos que se trata de un requisito indicativo, es decir, las secuencias dialogales y descriptivas pueden aparecer o no en un texto narrativo, dependiendo del carácter del mismo.

- Respecto a la adecuación en todos los textos analizados se mantiene un registro formal-culto, si bien aparecen algunas incursiones de nivel coloquial que no deterioran el conjunto de la narración. El propósito sigue las convenciones genéricas y todos los textos mantienen un punto de vista objetivo y una función informativa.

Los textos escritos presentan una caligrafía y una tipografía adecuada. Respecto a la ortografía, los errores más frecuentes son los relativos a los acentos tanto por omisión como por abundancia de los mismos.

- En relación a la cohesión, que quizás sea el aspecto que se evalúa con más rigidez, se ha intentado ver cuáles eran los ítems que aparecían en todas las composiciones, de los relacionados por el PCIC. Por lo tanto, como se ha podido comprobar, el análisis realizado no tenía como objetivo controlar los errores que se habrían podido producir, sino observar qué requisitos del elenco del PCIC aparecen en los textos y, a raíz de los resultados, comprobar si las rúbricas de evaluación eran factibles de aplicar para evaluar el nivel requerido. Por lo tanto, repetimos, el análisis no tiene como finalidad evaluar los textos, sino comprobar la validez de las rúbricas de evaluación.

En relación a los verbos propios de la narración, en los textos escritos aparecen todos los tipos verbales indicados por el Plan curricular.

Las oraciones subordinadas adverbiales que aparecen están bien coordinadas, aunque puede observarse algún error de concordancia, como se ha indicado más arriba. Respecto a las oraciones coordinadas, su uso es eficaz. Hay que señalar que en los relatos escritos todos los informantes utilizan una o varias subordinadas de las indicadas por el PCIC para el nivel B2.

La sustitución léxica se utiliza de manera eficaz en el 100\% de las producciones, sobre todo en el uso de catáforas y deícticos.

Respecto a los marcadores del discurso, en más de la mitad (53.3\%) de los textos orales y en el $46.6 \%$ de los escritos no aparecen los indicados por el PCIC para el nivel B2, lo cual no significa que lo textos no estén bien cohesionados, tanto en su macroestructura como en su mi- 
El desarrollo de la competencia narrativa en estudiantes nativos de español. Análisis e interpretación de una investigación con referentes fílmico-literarios

María Teresa Martín SánChez

croestructura, pues aparecen marcadores del discurso propios de otros niveles.

Posteriormente se han aplicado las rubricas de evaluación que se han elaborado ad hoc para este trabajo, con el fin de comprobar si los resultados obtenidos coinciden.

Cada una de las rúbricas se ha organizado expresando sintéticamente las categorías o criterios de competencia que se han utilizado en el modelo de análisis de datos procedentes de los textos en su formato respectivo (oral o escrito).

En balance, salvo excepciones importantes -como ocurre con el porcentaje bajo de recurrencia a los marcadores del discurso en el plano de la cohesión textual-, el 100\% de los alumnos nativos llega al nivel con valoraciones que van de satisfactorio a excelente, que corresponderían a notas que van de 7 a 10 .

\section{Conclusiones}

El alumnado ha experimentado el proceso comunicativo completo por trabajar la retroalimentación real en todas las dimensiones y habilidades posibles. Es decir, la tarea de aula ha entrenado a los alumnos en una acción de provecho social.

Queda demostrado que este modelo analítico-interpretativo ha permitido analizar minuciosamente el corpus de textos escritos generados a partir de la tarea intertextual y que para evaluar el grado de consecución del nivel B2 de dominio del español en los hablantes nativos dispone de una rúbrica de evaluación para cada una de las cualidades de textualización narrativa, todo lo cual, tras los resultados hallados con su aplicación, muestra su efectividad y utilidad tanto para el profesorado de español como lengua materna como para el de lengua extranjera, ya que existen numerosos modelos parciales de análisis de competencia comunicativa, pero el modelo COEN tiene la ventaja de proponer un diagnóstico global con un esquema de trabajo claro y manejable en el aula, que, a la hora de evaluar, extracta información mejor estructurada (y por tanto más comprensible por todos los agentes educativos) que la apreciación difusa sobre vocabulario, ortografía, concordancia o conectores, como suele hacerse habitualmente en las clases donde el profesor corrige el texto del alumno. 
El desarrollo de la competencia narrativa en estudiantes nativos de español. Análisis e interpretación de una investigación con referentes fílmico-literarios

María Teresa Martín SánChez

Las rúbricas de evaluación sirven al profesorado y al alumnado como hojas de ruta para entender desde el principio qué van a aprender y cómo van a ser valorados, lo cual les aporta una conciencia estratégica y corresponsable, más aún si el documento es claro y fácil de manejar, como pretende ser esta rúbrica

La utilidad del cine mudo y de su función intertextual con la literatura en el conjunto del modelo COEN apela a la idea de que un idioma no se aprende por imitación y repetición, sino por un proceso de globalización suscitado por inferencias e interpretaciones en contexto, gracias a los cuales pensamiento y lenguaje se unen para reconocer, conectar, crear y reflexionar sobre el mundo.

\section{Referencias}

Albert, M. J. (2007). La investigación educativa. Claves teóricas. Madrid: McGraw Hill Bajtín, M. M. (1986). Problemas de la poética de Dovtoievski. México: Fondo de Cultura Económica.

Bombini, G. (2005). La trama de los textos. Problemas de la enseñanza de la literatura. Buenos Aires: Lugar.

Caro, M. T. (2007). Imaginarios pictóricos de la literatura en el Museo de Bellas Artes de Murcia. Cartaphilus. Revista de Investigación y Crítica Estética, 2, 9-18. Recuperado de http://revistas.um.es/cartaphilus/article/download/734/777

Caro, M. T. (2015). Fundamentación científica de la Educación Literaria. En P. Guerrero y M.T. Caro (Coords.). Didáctica de la Lengua y Educación Literaria (pp. 261-288). Madrid: Pirámide.

Caro, M. T. (Coord.). (2014). Imago Mundi. Cine y literatura para el desarrollo y logro de la competencia en comunicación lingüística en Educación Secundaria. Murcia: Universidad de Murcia-Consejería de Educación, Cultura y Universidades de la Región de Murcia.

Caro, M. T. y González, M. (2012). Cine y literatura para educar en competencias básicas. En A. Mendoza y J. M. de Amo (Coords.). Perspectivas en investigación e innovación didáctica en recepción lectora: leer hipertextos (pp. 635-647). Almería: Editorial Universidad de Almería.

Caro, M. T. y González, M. (2013). De la mano de Cervantes: la lectura moderna de los clásicos. Octos, 9, 89-106. DOI: http://dx.doi.org/10.18239/ocnos_2013.09.05

Colomer, T. (2005). Andar entre libros. La lectura literaria en la escuela. México: Fondo de Cultura Económica.

Consejo de Europa (2002). Marco común europeo de referencia para las lenguas: aprendizaje, enseñanza y evaluación. Madrid: Ministerio de Educación, Cultura y Deporte, Secretaría General Técnica del MECD Subdirección General de Informaciones y Publicaciones y Grupo Anaya. MCER en español. Recuperado de http://cvc.cervantes. es/ensenanza/biblioteca_ele/marco/ 
El desarrollo de la competencia narrativa en estudiantes nativos de español. Análisis e interpretación de una investigación con referentes fílmico-literarios

María Teresa Martín SánChez

Eco, U. (1981). Lector in fabula. Barcelona: Lumen.

Fernández, S. (Coord.). (2001). Tareas y proyectos en clase. Madrid: Edinumen.

Fox, K. y Lambirth, A. (2012). Film and pedagogy: learning about teaching at the movies. En Bahloul, M. y Graham, C. (Eds.), Lights! Camera! Action and the Brain: The Use of Film in Education, 61-81. Newcastle Upon Tyne, UK: Cambridge Scholars Publishing.

Genette, G. (1989). Figuras III, Barcelona: Lumen.

González, M. (2013). El cine y la literatura en el desarrollo y logro de las competencias básicas. Análisis e interpretación de una investigación intertextual en Educación Primaria y Secundaria. (Tesis Doctoral). Murcia: Universidad de Murcia. Recuperado de http://digitum.um.es/xmlui/handle/10201/36742

González, M. y Caro, M. T. (2012). Estrategias didácticas intertextuales entre cine y literatura para la creación de un álbum ilustrado en Educación Primaria. En J. I. Alonso, A. Escarbajal y R. Nortes (Coords.) Experiencias de innovación en Educación Infantil y Educación Primaria (pp. 252-259). Murcia: EDITUM.

Guerrero, P. (2008). Metodología de investigación educativa (el modelo ekfrástico). Murcia: Editorial DM.

Guerrero, P. (2015). Literatura y Bellas Artes. En P. Guerrero y M.T. Caro (Coords.). Didáctica de la Lengua y Educación Literaria (pp. 365-376). Madrid: Pirámide.

Instituto Cervantes (2006). Plan curricular del Instituto Cervantes. Niveles de referencia para el español. Madrid: Biblioteca Nueva. Recuperado de http://cvc.cervantes.es/ ensenanza/biblioteca_ele/plan_curricular/default.htm.

Jauss, H. (1976). La literatura como provocación. Barcelona: Península.

Jiménez, J. (2005). La educación intercultural a través del cine. Granada: Port-Royal Ediciones.

Jonsson, A. y Svingby, G. (2007). The use of scoring rubrics: Reliability, validity and educational conséquences. Educational Research Review, 2, 130-144.

Kemmis, S. (1984). Point - by- point guide to action- research. Victoria: Dea Kin University.

Kemmis, S. y Mctaggart, R. (1988). Cómo planificar la investigación-acción. Barcelona: Laertes.

Latorre, A. (2003). La investigación-acción: conocer y cambiar la práctica educativa. Barcelona: Graó.

Lewin, K. (1973). Action research and minority problems. En K. Lewin. Resolving Social Coflicts. (201-216) Norwich, U. K.: Souvenir Press.

Martin, M. T. y Pascual, C. (2012). Análisis contrastivo de narraciones de estudiantes italianos e ingleses de ELE desde una perspectiva sociolingüística. Testi e linguaggi, 6, 129-145.

Martínez-Salanova, E. (1998). Aprender pasándolo de película. Comunicar. Revista científica iberoamericana de comunicación y educación, 11, 27-36. Recuperado de http://www.revistacomunicar.com/index.php?contenido=detalles\&numero=11 \&artic ulo=11-1998-05.

Mendoza, A. (2001). El intertexto lector. El espacio de encuentro de las aportaciones del texto con las del lector. Cuenca: Universidad de Castilla-La Mancha.

Mendoza, A. (Coord.) (2000). Lecturas de Museo. Orientaciones sobre la recepción de relaciones entre la literatura y las artes. Barcelona: Universitat de Barcelona. 
El desarrollo de la competencia narrativa en estudiantes nativos de español. Análisis e interpretación de una investigación con referentes fílmico-literarios

María Teresa Martín SánChez

Mendoza, A. (2006). El intertexto lector. En E. García (Coord.). La educación lingüística y literaria en Secundaria. Materiales para la formación del profesorado. Vol. 1 (pp. 93120). Murcia: Servicio de Publicaciones de la Consejería de Educación y Cultura de la Región de Murcia

Molina, C. (2015). Literatura e intertextualidad. Literatura y Pintura: ékfrasis creativa. En P. Guerrero y M.T. Caro (Coords.). Didáctica de la Lengua y Educación Literaria (pp. 399-412). Madrid: Pirámide.

Nunan, D. (1997). El diseño de tareas para la clase comunicativa. Cambridge: Cambridge University Press.

Panadero, E., Alonso-Tapia, J. y Reche, E. (2013). Rubrics vs. self-assessment scripts effect on self-regulation, performance and self-efficacy in pre-service teachers. Studies in Educational Evaluation, 39 (3), 125-132.

Pons, J. de P. (2009). El cine como factor de interculturalidad: una revisión globalizadora. En J. Ballesta (Coord.). Educar para los medios en una sociedad multicultural (pp. 119-127). Barcelona: Editorial davinci.

Romea, C. (1998). La narración audiovisual. En A. Mendoza (Coord.), Conceptos clave en Didáctica de la Lengua y la Literatura (pp. 347-357). Barcelona: ICE-Horsori.

Romea, C. (2003). El impacto del discurso literario y audiovisual. La iconotextualidad como motivación del intertexto lector. En A. Mendoza y P. C. Cerrillo (Coords.), Intertextos: aspectos sobre la recepción del discurso artístico (pp. 300-436). Cuenca: Ediciones de la Universidad de Castilla-La Mancha.

Puren, C. (2004). Del enfoque por tareas a la perspectiva co-accional. Porta Linguarun, 1, 31-36.

Romea, C. (2003). El impacto del discurso literario y audiovisual. La iconotextualidad como motivación del intertexto lector. En A. Mendoza Fillola y P. C. Cerrillo (coords.), Intertextos: aspectos sobre la recepción del discurso artístico (pp. 300-436). Cuenca: Ediciones de la Universidad de Castilla-La Mancha.

Romea, C. (2003). El impacto del discurso literario y audiovisual. La iconotextualidad como motivación del intertexto lector. En A. Mendoza y P. C. Cerrillo (Coords.), Intertextos: aspectos sobre la recepción del discurso artístico (pp. 300-436). Cuenca: Ediciones de la Universidad de Castilla-La Mancha.

Romea, C. (2008) ¿Cómo leemos en la era de Bill Gates? Una mirada postmoderna a los textos. En A. Mendoza (Coord.), Textos entre textos. Las conexiones textuales en la formación del lector (pp. 91-103). Barcelona: editorial Horsori.

Zanón, J. (1990). Los enfoques por tareas para la enseñanza de lenguas extranjeras. CABLE. Revista de didáctica del español como lengua extranjera, 5, 19-28.

Zanón, J. (Comp.) (1999). La enseñanza de E/LE mediante tareas. Madrid: Edinumen.

Zanón, J. y Estaire, S. (1990). El diseño de unidades didácticas en L2 mediante tareas: principios y desarrollo. Comunicación, Lenguaje y Educación. 7-8, 55-90. 
